\title{
Atypical hemolytic uremic syndrome post-kidney transplantation: two case reports and review of the literature
}

\author{
Sami Alasfar and Nada Alachkar* \\ Department of Medicine, Division of Nephrology, The Johns Hopkins University School of Medicine, Baltimore, MD, USA
}

\section{Edited by:}

Katsuhiko Asanuma, Kyoto University

Graduate School of Medicine, Japan

\section{Reviewed by:}

Sreenivasulu Gunti, National Institutes of Health, USA

Hideki Kato, University of Tokyo, Japan

\section{*Correspondence:}

Nada Alachkar, Department of Medicine, Division of Nephrology, The Johns Hopkins University School of Medicine, 600 Wolfe Street Brady 502, Baltimore, MD 21287, USA e-mail: nalachk1@jhmi.edu
Atypical hemolytic uremic syndrome (aHUS) is a rare disorder characterized by overactivation and dysregulation of the alternative complement pathway. Its estimated prevalence is 1-2 per million. The disease is characterized by thrombotic microangiopathy, which causes anemia, thrombocytopenia, and acute renal failure. aHUS has more severe course compared to typical (infection-induced) HUS and is frequently characterized by relapses that leads to end stage renal disease. For a long time, kidney transplantation for these patients was contraindicated because of high rate of recurrence and subsequent renal graft loss. The post-kidney transplantation recurrence rate largely depends on the pathogenetic mechanisms involved. However, over the past several years, advancements in the understanding and therapeutics of aHUS have allowed successful kidney transplantation in these patients. Eculizumab, which is a complement C5 antibody that inhibits complement factor $5 \mathrm{a}$ and subsequent formation of the membrane-attack complex, has been used in prevention and treatment of post-transplant aHUS recurrence. In this paper, we present two new cases of aHUS patients who underwent successful kidney transplantation in our center with the use of prophylactic and maintenance eculizumab therapy that have not been published before. The purpose of reporting these two cases is to emphasize the importance of using eculizumab as a prophylactic therapy to prevent aHUS recurrence post-transplant in highrisk patients. We will also review the current understanding of the genetics of aHUS, the pathogenesis of its recurrence after kidney transplantation, and strategies for prevention and treatment of post-transplant aHUS recurrence.

Keywords: aHUS, kidney transplant, eculizumab, genetic mutation, recurrence

\section{INTRODUCTION}

Atypical hemolytic uremic syndrome (aHUS) is a rare disorder characterized by over-activation and dysregulation of the alternative complement pathway. Its estimated prevalence is $1-2$ per million (1). The disease is characterized by thrombotic microangiopathy (TMA), which causes anemia, thrombocytopenia, and acute renal failure. aHUS has more severe course compared to typical (infection-induced) HUS and is frequently characterized by relapses that leads to end stage renal disease (ESRD). For a long time, kidney transplantation for these patients was contraindicated because of high rate of recurrence and subsequent renal graft loss. The post-kidney transplantation recurrence rate largely depends on the pathogenetic mechanisms involved. However, over the past several years, advancements in the understanding and therapeutics of aHUS have allowed successful kidney transplantation in these patients. Eculizumab, which is a complement C5 antibody that inhibits complement factor $5 \mathrm{a}(\mathrm{C} 5 \mathrm{a})$ and subsequent formation of the membrane-attack complex (MAC), has been used in prevention and treatment of post-transplant aHUS recurrence. In this paper, we present two new cases of aHUS patients who underwent successful kidney transplantation in our center with the use of prophylactic and maintenance eculizumab therapy that have not been published before. The purpose of reporting these two cases is to emphasize the importance of using eculizumab as a prophylactic therapy to prevent aHUS recurrence post-transplant in high-risk patients. We will also review the current understanding of the genetics of aHUS, the pathogenesis of its recurrence after kidney transplantation, and strategies for prevention and treatment of post-transplant aHUS recurrence.

\section{CASES}

CASE 1

In 2011, a 25-year-old Caucasian female developed ESRD due to aHUS. Her initial symptom was shortness of breath and she was found to have severe hypertension, acute kidney injury with serum creatinine of $11.4 \mathrm{mg} / \mathrm{dl}$, anemia with hemoglobin of $5 \mathrm{~g} / \mathrm{dl}$, elevated LDH, and thrombocytopenia with platelet count of 20,000/dl. Additional work-up revealed schistocytosis on peripheral smear. She underwent kidney biopsy that revealed TMA involving glomeruli and small vessels. A diagnosis of thrombotic thrombocytopenic purpura (TTP)/HUS was initially made. She received high-dose pulse steroids and four sessions of plasmapheresis. Despite therapy, the disease continued to progress and the patient became hemodialysis dependent. One year later, she 
was evaluated in our institution for kidney transplantation. Our work-up included ADAMTS13 level, which came back normal and genetic analysis, which confirmed a mutation (c.1933dup A) of complement factor-H (CFH), a variant in exon 13 (SCR11) of the gene CFH. This variant has been identified before and most likely associated with aHUS (personal communication with the Molecular research renal laboratory at the University of Iowa). In mid-2014, she underwent living unrelated kidney transplant. Twenty-four hours prior to transplantation, she received a dose of eculizumab $1200 \mathrm{mg}$ intravenously (IV). Immunosuppression consisted of induction therapy with four doses of intravenous thymoglobulin and 4-day methylprednisolone taper, and maintenance therapy with tacrolimus, mycophenolate mofetil, and prednisone. She had immediate graft function and her serum creatinine was $1.0 \mathrm{mg} / \mathrm{dl}$ at the time of discharge. After transplantation, she received weekly eculizumab $900 \mathrm{mg}$ IV for 4 weeks started on day 1 post-transplant, and then $1200 \mathrm{mg}$ IV biweekly starting at week 5 post-transplant; we have utilized the eculizumab protocol recommended by the manufacturing company. Serum complement 3 (C3) level was $37 \mathrm{mg} / \mathrm{dl}$ (normal 79-152 mg/dl) at the time of the transplantation and increased to $58 \mathrm{mg} / \mathrm{dl} 3$ months posttransplant. Haptoglobin and $\mathrm{LDH}$ levels were normal at the time of transplantation and remained normal afterwards. Hemoglobin was $9.5 \mathrm{~g} / \mathrm{dl}$ at the time of transplantation and increased to $12.5 \mathrm{~g} / \mathrm{dl}$ few weeks after. Renal allograft function has remained stable with most recent serum creatinine of $1.1 \mathrm{mg} / \mathrm{dl}$.

\section{CASE 2}

In 2002, a 23-year-old Caucasian female developed ESRD due to TMA disorder. Her initial presentation included nausea, vomiting, and jaundice. She was found to have evidence of hemolytic anemia with schistocytosis, thrombocytopenia, and acute renal failure. The initial diagnosis was thought to be TTP. She did not undergo a kidney biopsy. She was started on plasmapheresis but her disease did not respond to the treatment. She also received chemotherapy with vincristine with no response. Her hematologic parameters continued to worsen and eventually splenectomy was required. At the time of diagnosis, she was started on dialysis and remained dialysis depended thereafter. In 2003, she received living unrelated donor kidney transplantation. Her maintenance immunosuppressions were prednisone, mycophenolate mofetil, and sirolimus. In 2005, she developed a diarrheal illness, and her laboratory evaluation showed recurrence of thrombotic microangiopathy including hemolytic anemia, thrombocytopenia, and renal failure. At that time, she was initiated on plasmapheresis; however, her allograft function did not respond to the therapy and she was started again on dialysis. With the recurrence of TMA post-transplant, additional laboratory work-up revealed normal ADAMTS13 level and low C3 level. In 2012, she was evaluated for second kidney transplantation in our institution. Genetic testing was performed and revealed that the patient is heterozygous for two mutations in complement factor related proteins (CFHRs) that may cause aHUS. In fact, these two mutations were not identified previously in aHUS database. The mutations were deletion ( $\mathrm{CFH}$ int20brCFHR3) on allele 1 and duplication in (CFHR1 int4-CFHR4 block $7 / 2$ prime) on allele 2 . In early 2014, the patient received a successful six-antigen match deceased donor kidney transplant. A dose of eculizumab $1200 \mathrm{mg}$ was administered approximately $24 \mathrm{~h}$ prior to transplantation. After transplantation, she received weekly eculizumab $900 \mathrm{mg}$ IV for 4 weeks started on day 1 post-transplant, and then $1200 \mathrm{mg}$ IV biweekly started on week 5 post-transplant. At the time of transplantation, her hemoglobin was $11.2 \mathrm{~g} / \mathrm{dl}$ and haptoglobin level, LDH level, platelet count, and C3 level were all normal. Six months after transplantation, her hemoglobin increased to $13.5 \mathrm{~g} / \mathrm{dl}$. Haptoglobin level, C3 level, LDH, and platelets count remained within normal limits. Allograft function has been excellent so far with most recent serum Creatinine of $0.5 \mathrm{mg} / \mathrm{dl}$.

\section{ETIOLOGY}

Atypical HUS can be genetic, acquired, or idiopathic, whereas typical HUS (or diarrhea-associated HUS) is usually triggered by infection with certain strains of Escherichia coli that produce powerful Shiga-like exotoxins. There are also other forms of HUS that are secondary to other infections such as Streptococcus pneumoniae and HIV or secondary to malignancies, drugs, pregnancy, systemic lupus erythematous (SLE), and anti-phospholipid antibody syndrome $(2,3)$. More recently, HUS has been described in coagulation dysregulation disorders associated with mutations in certain genes; such as the gene encoding diacylglycerol kinase (DGKE) (4).

Atypical HUS is less common than other types of HUS and is characterized by a worse outcome $(1,2,5)$. Overall, aHUS accounts for $5 \%$ of all HUS cases (2). The incidence of aHUS in the United States is approximately 1-2 per million (1). Atypical HUS may develop in patients of any age, although the majority of cases develop in childhood $(1,2)$. The disease may have a familial or a sporadic pattern. Most of aHUS cases are linked to genetic abnormalities that involve genes encoding regulatory complement factors. The relationship between low-plasma C3 and HUS was first described by Cameron in 1973 (1, 2, 6). Several mutations in genes encoding regulatory complement proteins have been identified over the last decade. Atypical HUS is the result of abnormal activation and dysregulation of the alternative complement pathway.

\section{COMPLEMENT SYSTEM AND ITS REGULATION}

The alternative complement pathway is persistently activated in plasma. This activation is usually minimal and leads to minor attacks on all structures that the final complement product comes in contact with $(1,2,5,7)$. Under normal conditions, this process is very well regulated by regulatory complement factors. The alternative complement pathway is activated by the spontaneous hydrolysis of complement factor 3 (C3). C3 hydrolysis produces the fragment $\mathrm{C} 3 \mathrm{~b}$, which binds to complement factor $\mathrm{B}$ (CFB), which in turn is cleaved by complement factor $\mathrm{D}$ (CFD) to C3bBb, which is called the $\mathrm{C} 3$ convertase. This complex generates more $\mathrm{C} 3 \mathrm{~b}$ through an amplification loop. As the process continues, more $\mathrm{C} 3 \mathrm{~b}$ is produced, and eventually $[(\mathrm{C} 3 \mathrm{~b}) 2 \mathrm{BbP}]$ is formed. This complex acts as the $\mathrm{C} 5$ convertase that cleaves complement factor 5 (C5). Cleavage of C5 generates fragment C5b, which activates the terminal complement pathway by combining with complement factors $6,7,8$, and 9 to form C5b-9, the MAC. MAC is responsible for endothelial cell damage and leads to micro-thrombosis. 
To make this process regulated and prevent over-activation of the alternative complement pathway, different regulatory complement proteins are produced and activated under normal conditions $(1,2)$. Complement receptor 1 (CR1 or CD35), CFH, and decay-accelerating factor (DAF or CD55) compete with CFB in binding with $\mathrm{C} 3 \mathrm{~b}$ on the cell surface and can remove $\mathrm{Bb}$ from a $\mathrm{C} 3 \mathrm{bBb}$ complex. This leads to decreased C3 convertase production. The formation of a C3 convertase is also prevented by complement factor-I (CFI) that cleaves $\mathrm{C} 3 \mathrm{~b}$ into its inactive form. $\mathrm{CFI}$ requires a $\mathrm{C} 3 \mathrm{~b}$ binding protein co-factor such as $\mathrm{CFH}, \mathrm{CR} 1$, membrane co-factor protein (MCP or CD46), or thrombomodulin (THBD). CFH related proteins (CFHR1-5) comprise a group of five plasma proteins (CFHR1-5), and each member of this group binds to the central complement component C3b (8). The specific role of each CFHR protein in complement regulation remains unclear; however, they probably play an inhibitory role on C3 convertase and C5 convertase activity (8).

\section{GENETIC BASIS OF aHUS}

Atypical HUS is the result of abnormalities in the complement regulatory proteins mentioned above. These abnormalities lead to abnormal activation and dysregulation of the alternative complement pathway. Over the last several years, loss-of-function mutations have been identified in CFH, MCP, CFI, and THBD in some patients presenting with atypical HUS $(2,9)$. Anti-factor$\mathrm{H}$ and $\mathrm{I}$ antibodies have also been recognized in other patients, particularly in children. Gain-of-function mutations in C3 and CFB have also been identified in small percentage of patients with aHUS. Overall, mutations in complement regulatory factors or anti-factor-H and I antibodies have been documented in $60-70 \%$ of patients with aHUS $(2,5,9)$. The remainder of patients with aHUS probably have genetic abnormalities that yet to be identified. Most of the identified mutations have an incomplete penetrance. It is estimated that the penetrance for most of these mutations is about $50 \%(1,2,10-15)$. Table 1 summarizes the different characteristics of known mutation that have been associated with aHUS.

\section{Complement factor-H mutations}

These mutations are loss-of-function mutations. CFH mutations are the most frequent genetic abnormality identified in patients with aHUS (2). Up until now, eighty seven mutations in $\mathrm{CFH}$ associated with aHUS have been identified (16). They are found in $20-30 \%$ of aHUS patients (17-19). Seventy-five percent of the patients are heterozygous and the remainder is homozygous. In $30 \%$ of the patients, the mutations cause quantitative deficiency in $\mathrm{CFH}$ leading to decrease in $\mathrm{CFH}$ and $\mathrm{C} 3$ levels. The remainder has functional deficiency of CFH. In the latter case, $\mathrm{CFH}$ and $\mathrm{C} 3$ levels are usually in the normal range $(9,18,19)$.

\section{Anti-factor-H antibodies}

Auto-antibodies to CFH cause functional deficiency of CFH. They bind to factor- $\mathrm{H}$ and inhibit its binding to $\mathrm{C} 3 \mathrm{~b}(2,20,21)$. Antifactor- $\mathrm{H}$ antibodies are responsible for $6 \%$ of the aHUS cases. Low-C3 levels are observed in $40-60 \%$ of patients with antifactor-H antibodies. The majority of these patients also have other mutations in CFH, CFI, C3, CD46 (22), or mutations in genes encoding CFHR proteins $1-5$ such as deletions or rearrangements $(8,22,23)$.

\section{Membrane co-factor protein mutations}

These are loss-of-function mutations. The abnormal MCP binds weakly to C3b and loses its activity as co-factor $(1,2,9,17,24,25)$. Thus far, 28 mutations in MCP have been identified as a cause of aHUS (16). MCP mutations account for $10-15 \%$ of aHUS cases. They are more common in children than in adults. In up to $75 \%$ of the cases, MCP mutations cause low-MCP expression on peripheral leukocytes, which can be used as a diagnostic tool. However, in the remainder of cases, MCP mutations do not cause low-MCP expression (25). Around 30\% of patients with MCP mutations have low-C3 level $(2,5,7,9,17,25)$.

Table 1 | Characteristics of genetic mutations associated with aHUS and risk of recurrence after kidney transplantation without prevention or treatment.

\begin{tabular}{|c|c|c|c|c|}
\hline Mutation & aHUS incidence & Type of deficiency & C3 level & $\begin{array}{l}\text { Risk of recurrence } \\
\text { post-transplant }\end{array}$ \\
\hline $\mathrm{CFH}$ & $20-30 \%$ & $70 \%$ Qualitative and $30 \%$ quantitative & Low in $30 \%$ (quantitative deficiency) & $70-80 \%$ \\
\hline $\mathrm{CFI}$ & $5-10 \%$ & $70 \%$ Qualitative and $30 \%$ quantitative & Low in $30 \%$ (quantitative deficiency) & $70-80 \%$ \\
\hline C3 & $2-10 \%$ & Majority are quantitative & Low in $80 \%$ & $40 \%$ \\
\hline Anti-CFH Abs & $6 \%$ & $\mathrm{~N} / \mathrm{A}$ & Low in $40-60 \%$ & $\begin{array}{l}\text { 40-70\% Depending on } \\
\text { associated mutations }\end{array}$ \\
\hline CFHR 1-5 & Unknown & Usually qualitative & $\begin{array}{l}\text { Normal unless it is associated with } \\
\text { other mutations }\end{array}$ & Unknown \\
\hline
\end{tabular}

aHUS, atypical hemolytic uremic syndrome; C3, complement factor 3; CFH, complement factor-H; MCP, membrane co-factor protein; CFI, complement factorl; CFB, complement factor $B$; THBD, thrombomodulin; CFHR, complement factor-H related proteins. 


\section{Complement factor-I mutations}

These are loss-of-function mutations. CFI mutations account for $5-10 \%$ of aHUS cases $(21,26-28)$. To date, there are 11 mutations in CFI that have been associated with aHUS (16). Similar to CFH mutations, CFI mutations may lead to either a quantitative or functional deficiency in CFI. In $30 \%$ of the patients, the mutations cause quantitative deficiency in CFI leading to decrease in both CFI and C3 levels (2, 7, 9, 21, 26-28).

\section{Thrombomodulin mutations}

These are also loss-of-function mutations. Cells with mutant THBD are less efficient at inactivating C3b. THBD mutations account for 3-5\% of patients with aHUS. C3 levels are low in $50 \%$ of patients THBD mutations $(2,7,9,12,29)$.

\section{Complement factor $B$ mutations}

Complement factor B mutations are usually gain-of-function mutations and result in increased stability of $\mathrm{C} 3$ convertase and its resistance to degradation. CFB mutations account for $1-4 \%$ of patients with aHUS $(7,30)$. Patients with CFB mutations always have low-serum C3 level (2, 7, 9, 30-32).

\section{Complement component 3 mutations}

The mutant $\mathrm{C} 3$ binds weakly to MCP and/or CFH, which leads to indirect gain-of-function for $\mathrm{C} 3$ activity $(7,33)$. Therefore, binding of CFB to $\mathrm{C} 3 \mathrm{~b}$ increases and more $\mathrm{C} 3$ convertase is formed. C3 mutations account for $2-10 \%$ of patients with aHUS. In $80 \%$ of cases, serum C3 level is low $(2,7,9,32,33)$.

\section{Combined mutations}

Up to $10-12 \%$ of patients with aHUS have two or more mutations in different complement factors (32). This suggests that aHUS may result from the additive effects of several genetic factors (2).

\section{Complement factor-H related proteins genetic polymorphism}

Genetic polymorphisms in CFH related proteins may create a slight increase in predisposition to aHUS and could influence the severity of disease $(7,8,26,34-36)$. The area of abnormalities in genes encoding CFHR proteins still needs further investigation. Mutations, genetic deletions, duplications, or rearrangements in the individual CFHR genes are associated with a number of diseases including aHUS, C3 glomerulopathy, IgA nephropathy, age related macular degeneration (AMD), and SLE (36). Rearrangement that leads to the formation of hybrid CFH/CFHR1 gene has been associated with aHUS $(7,37)$. A hybrid factor-H/CFHR3 gene generated by a microhomology-mediated deletion was reported in a familial aHUS case (38). Deletion of CFHR1/CFHR3 is also strongly associated with the development of factor- $\mathrm{H}$ autoantibodies (36, 39-41). CFHR1 deficiency alone could modulate the severity of aHUS associated with another mutation (26). Genetic variants of CFHR5 were also reported in aHUS patients $(33,42)$.

\section{RISK OF RECURRENCE}

Atypical HUS, unlike infection-induced HUS is associated with very high risk of recurrence after kidney transplantation $(5,43)$. Concern over the recurrence of HUS after kidney transplantation has been recognized for a long time $(44,45)$. In 2003, Loirat and Niaudet (43) studied the risk of recurrence of HUS after kidney transplantation in children and found that the risk in patients whose original HUS was not associated with diarrhea is higher compared to the infection-induced HUS. Sixty-three children, who had the non-diarrheal HUS, received 77 kidney transplants. Thirteen patients $(21 \%)$ had recurrence of HUS after one or more grafts, and there were a total of 18 recurrences in 77 grafts (23\%). In later observational studies, the recurrence rate of HUS in adult patients who received kidney transplantation was as high as $50-60 \%(7,43,46-48)$.

Over the past few years, several studies have assessed the risk of post-transplant aHUS recurrence and prognosis associated with specific genetic abnormalities $(7,17,24,49,50)$. The recurrence rate after transplantation in aHUS patients essentially depends on whether the mutant complement factor is membrane-bound or circulating. Membrane-bound factors expression in the renal allograft is determined by the donor genome. Thus, patients with mutations in genes encoding one of these factors are not expected to develop post-transplant aHUS recurrence. On the other hand, the risk of post-transplant aHUS recurrence in patients with mutations encoding circulating factors is expected to be high $(5,7,24$, 49, 51).

In two French case series $(24,51)$, the rate of post-transplant aHUS recurrence in patients with $\mathrm{CFH}$ mutations was around $75-80 \%$ in 5 children and 16 adults who received 6 and 17 renal transplants, respectively. Around the same recurrence rate was noted in a 2006 meta-analysis of 36 renal transplantations in 27 patients with aHUS associated with $\mathrm{CFH}$ mutations (49). Recurrence of aHUS with this type of mutation was associated with poor prognosis, leading to graft loss in $93 \%$ of patients (49).

In patients with anti-CFH antibodies, the risk of posttransplant aHUS recurrence is not well known. Studies so far only described a total of 12 kidney transplantations in eight patients $(1,7,22,35,52-54)$. The assessment of the risk is further complicated by the finding that as many as $40 \%$ of patients with anti-CFH antibodies also carried a mutation in genes encoding complement regulatory factors, including $\mathrm{CFH}, \mathrm{CFI}, \mathrm{MCP}$, and $\mathrm{C3}$ (22). Initially, it was thought that reduction in levels of anti-CFH antibodies with plasmapheresis and rituximab permitted successful kidney transplantation in these patients, suggesting that high anti-CFH antibody levels positively correlate with risk of posttransplant aHUS recurrence $(52,53)$. However, later publications have reported that recurrence-free transplantation is achievable in patients with anti-CFH antibodies despite the absence of any specific treatment $(22,53,54)$.

In aHUS patients with CFI mutations, the post-transplant recurrence rate is high and associated with poor prognosis $(1,7$, $18,20,21,24,55-58)$. Available publications reported 10 patients, who received 15 kidney transplants. 12 of $15(80 \%)$ transplants consecutively failed because of aHUS recurrence. In a paper from 2009 (26), it was found that more than half of the CFI-mutation patients had an additional genetic susceptibility for aHUS and that those with an isolated CFI mutation had improved kidney survival over those with additional mutations. Thus, the post-transplant risk of aHUS recurrence for patients with a CFI mutation should be reassessed in the light of this finding. 
Atypical HUS patients with MCP mutations are expected to have a low risk of post-transplant aHUS recurrence because MCP is a membrane-bound protein $(7,59)$. Therefore, the prognosis of patients with $M C P$ mutations after kidney transplantation is much better than that of patients with mutations in $C F H$ and $C F I(7,18,24,25,59,60)$. However, a recent large study of aHUS patients revealed the unexpected recurrence of disease after transplantation in some carriers of MCP mutations. This is probably explained by the fact that a significant proportion $(22.6 \%)$ of patients with mutations in MCP also carried mutations in genes encoding circulating complement factors (61). Notably, post-transplant recurrence occurred in 7.6 and 30\% of MCP single-mutated and MCP-combined mutated patients, respectively (61). In our previously published series (62), the only patient who had MCP mutation did not develop disease recurrence after kidney transplantation.

There is very limited data on the post-transplant recurrence of aHUS in patients with THBD mutations. THBD exists both in membrane bound and soluble forms, hence, it is not possible to reliably predict the risk of post-transplant recurrence in carriers of these mutations. In the available study (12) that describes seven patients with THBD mutations, one individual experienced posttransplant recurrence of aHUS. In another case report (29), a 19year-old man with aHUS secondary to a THBD mutation relapsed twice after two kidney transplantations performed 12 years apart, which suggests that THBD mutations may favor-relapse of aHUS after kidney transplantation. In our previously published series (62), there was one patient with THBD mutation who developed early recurrence after kidney transplantation.

Atypical HUS patients with C3 mutations have reduced risk of recurrence after transplantation although it remains high after all (7). In a study that reported 12 kidney transplant recipients with C3 mutations, 5 of them (42\%) developed recurrence (1, 11). Most circulating C3 is synthesized by hepatocytes; however, smaller though significant amounts are produced in other tissues including the kidney. Therefore, it is possible that production of non-mutant $\mathrm{C} 3$ by the graft might account for the reduced recurrence rate $(63,64)$.

In aHUS patients with CFB mutations, there are four cases reported and in all four transplants failed because of recurrence $(7,10,65)$.

\section{POST-TRANSPLANT aHUS RECURRENCE TRIGGERS}

The natural history of aHUS in kidney transplant patients varies from that of non-kidney transplant patients $(1,5,7)$. The recurrence of aHUS in transplants patients usually occurs within the first year after transplantation $(5,49,51)$. This is different from non-transplant patients in whom the onset of aHUS is frequently delayed, with up to $50 \%$ of cases presenting in adulthood (5, 66). This difference is probably driven by the environment that kidney transplantation creates, in which multiple potential triggers for aHUS recurrence exist. A meta-analysis in 1998 (67) attempted to identify clinical risk factors associated with high risk of aHUS recurrence in post-transplant patients. The study concluded that old age at presentation, short duration between onset of disease and ESRD or transplantation, use of living donors, and use of calcineurin inhibitor (CNI) are all associated with high risk of recurrence. It has been suggested that recurrence after transplantation may be less common among patients who have undergone a nephrectomy prior to transplantation. However, there is only once study that reported this observation. In this study, pooled data from several series was analyzed, and recurrence was reported among 5 of 14 patients who had undergone nephrectomy compared with 27 of 35 patients who had not undergone nephrectomy (47).

There are different mechanisms in the kidney transplantation process that may trigger recurrence of aHUS including brain-death related injury, ischemia-reperfusion injury, infections, the use of immunosuppressive drugs, and rejection (5).

There is growing evidence about the role of complement activation in brain-death-induced organ injuries $(5,68,69)$, which could be a trigger for aHUS recurrence. In brain death, there is an increased circulating C5a level that induces a release of proinflammatory cytokines by the kidney and eventually leads to increased formation of C5b-9 complex.

Ischemia-reperfusion leads to endothelial damage in kidney allograft. Studies proposed that this damage causes reduced $\mathrm{CFH}$ ability to bind to the endothelium (70), ongoing alternative pathway activation, and increased formation of C5b-9 (5). Given this possible role of complement activation in the pathology of delayed graft function, there are several clinical trials that are underway to assess the efficacy of eculizumab in prevention of delayed graft function in deceased donor kidney transplantation (www.Clinicaltrials.gov NCT01919346).

Many infections have been involved in triggering posttransplant aHUS recurrence (5). These include CMV (71), influenza virus (72-74), parvovirus B19 (75), BK virus (76), upper respiratory tract infection $(19,77)$, and infectious gastroenteritis $(19,78)$.

Also, immunosuppressive drugs could trigger post-transplant aHUS recurrence $(2,5,7)$. Both calcineurin- and mTOR inhibitors have been associated with endothelial toxicity $(79,80)$ and posttransplant TMA. Prolonged CNI-related ischemia is believed to induce endothelial damage and initiate the pathogenic processes involved in the development of TMA $(7,81)$. Despite the general idea that CNI play a prominent role in stimulating post-transplant aHUS, the only available study that assessed the risk of aHUS recurrence with different drugs showed that mTOR inhibitorbased regimens only were found to be an independent risk factor for post-transplant aHUS recurrence (51). In contrast, this study failed to identify CNI-based regimens as risk factors for posttransplant aHUS recurrence. In addition, other studies found that mutations in CFH and CFI genes were identified in 30\% of transplant recipients with CNI-induced de novo post-transplant aHUS $(5,7,82)$. This suggests that factors, resulting in complement overactivation may be required for $\mathrm{CNI}$-induced endothelial toxicity to clinically manifest. Interestingly, in the context of post-transplant CNI toxicity, systemic aHUS, unlike localized renal TMA, usually fails to respond to reduction or temporary discontinuation of CNI therapy (83) and respond dramatically to complement blockade (84). In an attempt to reduce the burden of insults to the graft endothelium, the CTLA-4-Ig fusion protein belatacept, which does not cause any endothelial toxicity, might be a promising alternative to calcineurin and mTOR inhibitors for maintenance 
immunosuppressive regimens but this drugs needs to be further investigated (7).

Rejections could also trigger post-transplant aHUS recurrence (7). The renal allograft endothelium is the primary target of antiHLA antibodies. Although antibodies activate the complement cascade primarily through the classical pathway, one can reasonably hypothesize that uncontrolled activation of the alternative pathway in aHUS patients could further amplify the endothelial damages induced by anti-HLA antibodies.

\section{CLINICAL PRESENTATION}

Patients with post-transplant aHUS usually present with a microangiopathic hemolytic anemia, thrombocytopenia, and acute kidney injury. Typical laboratory abnormalities include an increased serum creatinine; evidence of hemolysis (such as increased reticulocyte percentage, reticulocytosis, schistocytes on peripheral smear, and increased serum lactate dehydrogenase); and a low-platelet count. The urinalysis typically shows hematuria and only a small amount of proteinuria. Patients with post-transplant aHUS recurrence may develop fever but the presence of chills and high-spiking fever should suggest that the presence of infection that could be the trigger of aHUS recurrence. Recurrence could also manifest with neurological symptoms such as confusion and headache. Focal neurological abnormalities (e.g., transient aphasia, transient ischemic attack, and stroke) are less frequent, but grand mal seizures and coma can occur. Imaging studies may show a pattern consistent with reversible posterior leukoencephalopathy syndrome (PRES) (85). Gastrointestinal symptoms of aHUS include abdominal pain, nausea, vomiting, and diarrhea. Cardiac involvement includes diffuse platelet thrombi and associated hemorrhage and patches of necrosis in cardiac tissues (e.g., coronary arteries, myocardium, and conducting system), which may lead to complications such as arrhythmia, sudden cardiac death, and myocardial infarction (86).

Some patients may present with only an increased serum creatinine and abnormal urinalysis due to the renal lesion associated with TMA, and without thrombocytopenia, hemolytic anemia, or other manifestations $(45,87)$. In 2014 , Stevenson et al. (88) described a case of unsensitized aHUS patient who received deceased donor kidney transplant. The patient developed severe antibody mediated rejection (AMR) that was unresponsive to aggressive therapy with evidence of new DSA formation. The rejection led to graft failure. This case suggested that dysregulation of the alternative complement pathway within the transplanted kidney may have contributed to the severe AMR. Licht et al. (89) reported an AMR case, presenting with a systemic thrombotic microangiopathic process, in a kidney transplant recipient harboring a homozygous deletion of CFHR3-1. In this patient, eculizumab rescue therapy rapidly resulted in a complete recovery from the AMR-induced TMA, further supporting the benefit of complement blockade in severe AMR. There is an ongoing trial that is currently underway to study the efficacy and safety of Eculizumab for treatment of AMR following kidney transplantation (www.ClinicalTrials.gov NCT01895127).

The differential diagnosis of post-transplant aHUS recurrence after kidney transplantation is similar to that of non-kidney transplant patients. This includes TTP and secondary forms of HUS due to other causes. Shiga toxin-producing E. coli (STEC) induced HUS is differentiated from aHUS based on demonstrating a recent exposure to STEC. Thus, screening for STEC should be performed in these cases. S. pneumoniae induced HUS occurs in a patient with evidence of a pneumococcal infection (e.g., pneumonia, sepsis, or meningitis), which is confirmed by a positive culture of blood and/or other pertinent tissues. HIV infection should also be excluded. Other rare non-infectious secondary causes of HUS include drug toxicity (examples: quinine, anti-platelet therapy, and chemotherapy), and autoimmune diseases like SLE or antiphospholipid syndrome. HELLP syndrome and post-partum HUS should be kept on the differential diagnosis if the history is suggestive; although recent data showed that complement mutations were described in $36 \%$ of women with HELLP syndrome and $86 \%$ of cases of post-partum HUS. Thus, we may conclude that pregnancy could act as a trigger for aHUS rather than a direct cause of it.

\section{PREVENTION}

For many decades, kidney transplantation was contraindicated for patients with ESRD secondary to aHUS due to the highrecurrence rate. However, over the last decade, perceptions on kidney transplantation in aHUS have changed. Transplantation may now be considered on a case-by-case basis, with individualized strategies based on donor characteristics and recipient genetics findings $(5,7,90)$. Certain strategies that primarily target preventing endothelial damage, that could potentially trigger aHUS in renal allograft, can be used to make the kidney transplantation successful. As mentioned earlier, the kidney transplantation process leads to transient or continuous endothelial damage in different mechanisms. This damage may serve as the trigger to alternative complement pathway activation and subsequently recurrence in aHUS. These insults are discussed earlier, and include brain death, ischemia/reperfusion injury, infections, immunosuppressive drugs, and rejection. In theory, strategies that minimize or halt these insults may lead to better renal allograft outcome.

As mentioned earlier, brain death and ischemia-reperfusion play a role in complement activation. Thus, aHUS patients, who are prone to uncontrolled complement activation, may be more susceptible to delayed graft function and ischemia-induced irreversible graft damage $(5,51)$. Therefore, it seems reasonable to exclude expanded criteria donors with the greatest risk of delayed graft function, such as non-heart-beating donors or those with prolonged cold ischemia times, from donation to aHUS patients. Also, to reduce the burden of post-transplant endothelial damaging factors, renal transplantation across positive crossmatches and/or with preformed donor specific antibody should be evaluated carefully, especially in patients who are highly sensitized and incompatible donation is the only option available for transplantation. In our previously published series, few patients with aHUS received ABO and HLA incompatible kidney transplantation (62).

Systemic infections have been found to trigger aHUS episodes. Thus, infections in kidney transplant recipients with aHUS must be treated aggressively to prevent aHUS recurrence. Particular attention must be paid to preventing CMV infection with adequate prophylaxis in kidney transplant recipients with aHUS $(5,71,91)$. 
In terms of immunosuppressive drugs, although CNI have been associated with endothelial toxicity $(79,80)$ and post-transplant TMA, a cohort study failed to identify CNI-based regimens as risk factors for post-transplant aHUS recurrence (51). However, CNI overexposure may trigger aHUS recurrence, emphasizing the need of careful CNI blood levels monitoring. On the other hand, mTOR inhibitors have been independently associated with a greater aHUS recurrence rate, and should not be used in aHUS patients $(5,51)$. Belatacept therapy that has no risk on endothelial injury should be studied further; it may be considered an alternative maintenance immunosuppressive therapy in these patients $(5,7)$.

\section{TYPE OF TRANSPLANT}

The type of transplant may play a role in prevention of posttransplant aHUS recurrence. There are two options for kidney transplantation in patients with aHUS. This includes combined liver-kidney transplantation (CLKT) and isolated kidney transplantation.

\section{Combined liver-kidney transplantation}

The motivation to treat individuals with ESRD due to aHUS by CLKT is that liver transplant represents the "gene therapy" for those individuals whose aHUS is due to a defect in a circulating product synthesized by the liver. However, the early experiences with CLKT were disappointing. The first five cases did not include preoperative treatment with plasma therapy and had a fatal outcome. In three of these cases, there was evidence of complementmediated coagulative hepatic necrosis (5, 92-94). As mentioned earlier, it is suggested that with ischemia/reperfusion, significant modification in the endothelial happens leads to complement activation $(95,96)$. Thus, it was suggested that CLKT should not be done without a preoperative regimen for complement regulation such as plasma therapy, or anti-C5 treatment with eculizumab. Unfortunately, there is no registry that gathers and follows the outcome of aHUS cases that were treated with liver or combined liver and kidney transplantation. A summary of more recent cases that were treated with liver or CLKT was published in 2013 (97). These cases were also treated with preoperative eculizumab or plasma therapy. The overall success rate was 16 out of $20(80 \%)$ and the mortality rate was 3 out of 20 (15\%). Out of 20 transplants, 16 were carrier of CFH mutations (14 successful), 1 for CFB (successful), 1 for C3 (unsuccessful), and 2 for CFH/CFHR1 hybrid mutation (1 successful). One successful transplant was an isolated liver in a patient with remaining kidney function before the availability of eculizumab. Plasma therapy alone was used in 18 ( 15 cases successful) and eculizumab with plasma therapy in 2 (1 successful).

Nevertheless, the risks inherent to the surgery and the safer newly available alternative preventative and therapeutic options have made CLKT less favorable for treatment of aHUS. Thus, the option of CLKT should be pursued on a case-by-case basis, depending on individual's physical status, local expertise of the transplant surgeons, ability to afford a long-term eculizumab therapy, and patient wishes regarding quality-of-life $(5,90)$.

\section{Isolated kidney transplantation}

Over the last several years, advancements in the management of aHUS have allowed successful isolated kidney transplantations in patients with ESRD secondary to aHUS. There is no longer rationale for barring kidney transplantation in aHUS patients from deceased donors and from living non-related donors, provided that anti-C5 treatment with eculizumab is available for preventing or treating aHUS recurrence. Prior to transplantation, many centers screen patients for genetic abnormalities in complement regulatory proteins before inclusion on kidney transplant waiting lists. It is not acceptable to do the distinction between infectioninduced HUS and aHUS based on prodromic diarrhea alone, because approximately $20-30 \%$ of cases of aHUS are preceded by diarrhea $(7,24)$. In the case of living donors, most centers screen donors and exclude them if they are found to carry mutations in the above-mentioned genes. Historically, living-related kidney transplantation was contraindicated in aHUS patients in most centers (1) because of the risk of the donor carrying the same mutation that the recipient has. However, this recommendation had changed with the recent approaches that have been used for prevention and treatment of aHUS post-transplantation recurrence.

\section{PLASMA THERAPY/PLASMAPHERESIS}

There is limited published data on the efficacy of prophylactic plasma therapy to prevent post-transplant aHUS recurrence. It was first demonstrated to be efficient in preventing post-transplant aHUS recurrence in patients in whom genetic abnormalities predicted a high risk of recurrence following kidney transplantation $(5,51,53,61,91)$. However, in other studies, prophylactic plasma therapy failed to prevent post-transplant aHUS recurrence in some cases $(51,98)$. In a small sample study $(51)$, nine patients received preemptive plasma exchange therapy in an attempt to prevent post-transplant recurrence of aHUS. In multivariate analysis, prophylactic plasma therapy decreased graft loss $[R R=0.11(0.01-$ 0.84) $p=0.035]$. There was also a non-significant decrease in disease recurrence $[R R=0.34(0.10-1.13) p=0.078]$ in patients who received preemptive plasma exchange therapy. In addition to this, some small studies demonstrated that there was an unpredictable risk of recurrence when plasmapheresis sessions were progressively spaced out $(5,59,91)$. Lastly, the issues of prolonged adequate vascular access (5), plasma allergy (59), and quality-oflife (99) should also be taken into account when treating with long-term plasma therapy. In antibody-induced aHUS (e.g. anti$\mathrm{CFH}$ antibodies), preventative plasmapheresis is the therapy of choice. In recent papers, attempts to reduce titers of anti-CFH antibody with preemptive plasmapheresis and/or rituximab have enabled successful kidney transplantation in two patients with aHUS-related ESRD (5, 100, 101).

\section{ECULIZUMAB}

Eculizumab is a recombinant humanized monoclonal anti-C5 antibody, licensed initially for the treatment of paroxysmal nocturnal hemoglobinuria $(2,102)$, was recently approved for the treatment of aHUS (2). Eculizumab binds specifically to the complement protein $\mathrm{C} 5$, halting the complement cascade and inhibiting production of cell-killing protein complexes (103).

In 2011, Weitz et al. (77) reported the first successful kidney transplantation in a child with CFH deficient aHUS after the prophylactic administration of eculizumab. In 2012, Zuber et al. 
(98) in France reported nine patients who received prophylactic eculizumab therapy to prevent post-transplant aHUS recurrence, eight of whom experienced a successful recurrence-free posttransplant course, while one lost his graft from an early graft artery thrombosis. They all harbored a complement genetic abnormality associated with a risk of aHUS recurrence $>80 \%$. Recently, our institution (62) reported four patients with aHUS who received prophylactic eculizumab at the time of transplantation. Three of them received eculizumab for 6 months post-transplant and one of them received it as life-long therapy. The four patients did not develop aHUS recurrence. Earlier in this paper, we included two new cases of aHUS caused by CFH and CFHRs mutations that underwent successful kidney transplantation with prophylactic life-long eculizumab.

Overall, these data suggest that long-term eculizumab treatment is highly effective for the prevention of post-transplant aHUS recurrence. More studies are needed to determine the optimal dosing and duration of prophylactic therapy (90).

There are no established guidelines for eculizumab dosing in prevention of aHUS. In our institution, the first dose is administered within $24 \mathrm{~h}$ before the operation. Prophylactic strategy should be initiated before the surgery in order to hamper ischemiareperfusion injury related complement activation. We continue with weekly infusion starting on day 1 post-transplant for 4 weeks, then biweekly infusion. The decision when to stop eculizumab therapy is based on the patient's mutation type. We currently recommend life-long therapy for patients with mutations that are associated with high-recurrence rate such as $\mathrm{CFH}, \mathrm{CFI}$, and $\mathrm{CFB}$ mutations.

\section{TREATMENT}

\section{PLASMAPHERESIS}

Earlier studies did not show good outcome with plasmapheresis alone in the treatment of post-transplant aHUS recurrence. In Noris et al. paper (1), plasma therapy induced remission in 55$80 \%$ of episodes in patients with $\mathrm{CFH}, \mathrm{C} 3$, or THBD mutations or auto-antibodies, whereas patients with CFI (factor-I) mutations were poor responders. In Le Quintrec's (51) paper, curative plasma therapy, which consisted either of fresh frozen plasma infusions $(n=3)$ or plasma exchanges $(n=30)$, was performed in 33 of the 44 patients $(75 \%)$ with aHUS recurrence. Overall, graft outcome was poor in patients who received curative plasma therapy for recurrence in univariate analysis $[R R=2.51(1.34-4.68)$ $p=0.004]$. After adjustment for recurrence, multivariate analysis showed that curative plasma therapy did not improve graft survival $[\mathrm{RR}=1.17(0.49-2.83) p=0.7]$.

\section{ECULIZUMAB}

There are multiple case reports and series that showed success with eculizumab in the treatment of plasmapheresis resistant (104-106) and dependent aHUS forms (99, 104, 106-108). There are also some cases where eculizumab was also used as a first line therapy without any prior plasma therapy $(106,109)$.

In 2011, Al-Akash et al. (72) reported one case in which eculizumab with plasmapheresis induced long-term remission in recurrent post-transplant aHUS associated with $\mathrm{C} 3$ gene mutation. In 2012, we reported a case of two post-transplant aHUS recurrences in a patient with unclassified aHUS. The first recurrence responded to plasmapheresis and eculizumab. The second recurrence was treated successfully with eculizumab alone (104). Zuber et al. (98) also reported thirteen kidney transplant recipients were given anti-C5 for post-transplant aHUS recurrence. A complete reversal of aHUS activity was achieved in all of them. In this case series, it was noted that the delay of anti-C5 initiation after the onset of the aHUS episode inversely correlated with the degree of renal function improvement. Three patients in whom anti-C5 was subsequently stopped experienced a relapse. Recently, we presented our center's data (62), in which three patients with post-transplant aHUS recurrence after kidney transplantation were treated with eculizumab and plasmapheresis, two of them responded to the therapy. The patient who did not response had CFH mutation.

Legendre et al. (107) have recently published the results of two trials that studied the efficacy of eculizumab in adults and adolescents with aHUS resistant to plasma therapy (trial $1 ; 17$ patients) or on chronic plasma therapy (trial 2; 20 patients). These two trials together included 15 kidney transplant recipients. In both trials, the primary end point (i.e., normalization of platelet count and TMA-free status, respectively) was achieved by more than $80 \%$ of the patients. Interestingly, similar to Zuber's paper, it was noted that there was an inverse correlation between the onset of the aHUS recurrence and eculizumab initiation with the recovery of renal function in both transplanted and non-transplanted patients. In these 2 studies, 5 out of 18 patients who missed eculizumab doses developed post-transplant aHUS recurrence. In two case reports, patients received only a single dose for the treatment of recurrent post-transplant aHUS $(104,105)$. Although both patients had sustained response with a prolonged aHUS-free period, delayed recurrence occurred in the first patient after 11.5 months (105) and in the other after 21 months (104). The reintroduction of eculizumab led to remission of aHUS in the former patient but failed to prevent graft loss in the later. In another case report, a delay of 6 days in the ninth infusion of eculizumab led to a mild relapse of post- transplant aHUS, but the disease responded rapidly to the re-initiation of treatment (110).

The studies above illustrate the importance of prompt treatment with eculizumab therapy once a recurrence is diagnosed. They also show that maintenance treatment is more effective than single dose therapy in preventing recurrence. There is also a suggestion that more recurrence occurs when administration of eculizumab is spaced out by more than every 2 weeks. Altogether, the available data also illustrate the critical need for prospective well-controlled studies to address the issue of treatment dosing and duration.

\section{FUTURE THERAPIES}

Concentrated $\mathrm{CFH}$, purified from human plasma, may serve as a future therapeutic option for aHUS patients with $\mathrm{CFH}$ mutations, especially in patients with a quantitative deficiency in functional $\mathrm{CFH}(5,7)$. However, there are several questions that need to be addressed regarding its therapeutic efficacy, bioavailability, potential dosing, and complications relating to competition between the plasma-derived $\mathrm{CFH}$ and the mutated protein. Also, recombinant THBD can be utilized in the treatment of aHUS (12). The use 
of recombinant human THBD, which also has anticoagulant and anti-inflammatory properties, was approved in Japan in 2008 for the treatment of disseminated intravascular coagulation. Of note, a case of refractory TMA after hematopoietic stem cell transplantation was published in 2009; the TMA was successfully treated with recombinant THBD (111). Other complement-modulating agents under development might represent additional therapeutic avenues (112) and need more investigation.

\section{SUMMARY}

Atypical HUS is characterized by hemolytic anemia, thrombocytopenia, and renal impairment that frequently progresses to ESRD. In more than $50 \%$ of patients, mutations in complement regulatory proteins or antibodies to these proteins are identified. Among patients who undergo kidney transplantation, aHUS commonly recurs, especially in patients who carry mutations. Recurrent aHUS after kidney transplantation is associated with high rate of allograft failure. The type of the mutation dictates the overall prognosis and the risk of post-transplant recurrence, which ranges from very minimal up to $80 \%$. Although combined liver and kidney transplantation provides the "gene therapy" for aHUS, it remains a high-risk operation and with the successful use of eculizumab in prevention and treatment of post-transplant aHUS recurrence, this option became less favorable, although it should not be overlooked. Isolated kidney transplantation remains the best option for ESRD due to aHUS. Nonetheless, in the milieu of kidney transplantation, there are several triggers for aHUS recurrence and this includes immunosuppressive drugs, brain-death related injury, ischemia-reperfusion injury, and infections. Strategies that minimize or block these potential triggers could prevent aHUS recurrence. The available published data strongly suggest that the use of prophylactic treatment with eculizumab rather than plasmapheresis alone. With the limited available data, eculizumab should be continued indefinitely. Among all transplantation recipients who develop recurrence in aHUS after transplantation, treatment with eculizumab rather than plasmapheresis alone should be promptly initiated. However, therapy with eculizumab carries its own risks and is associated with meningococcal infections that can be life threatening. Thus, meningococcal vaccination is required in all patients treated with eculizumab. There are several questions regarding the safety, dosing, and duration of prophylaxis and/or treatment with this drug. The best approach to answer these questions can be achieved by a prospective controlled trial.

\section{REFERENCES}

1. Noris M, Remuzzi G. Atypical hemolytic-uremic syndrome. N Engl J Med (2009) 361:1676-87. doi:10.1056/NEJMra0902814

2. Salvadori M, Bertoni E. Update on hemolytic uremic syndrome: diagnostic and therapeutic recommendations. World J Nephrol (2013) 2:56-76. doi:10.5527/wjn.v2.i3.56

3. O'Brien AO, Lively TA, Chen ME, Rothman SW, Formal SB. Escherichia coli O157:H7 strains associated with haemorrhagic colitis in the United States produce a Shigella dysenteriae 1 (SHIGA) like cytotoxin. Lancet (1983) 1(8326 Pt 1):702. doi:10.1016/S0140-6736(83)91987-6

4. Lemaire M, Frémeaux-Bacchi V, Schaefer F, Choi M, Tang WH, Le Quintrec $\mathrm{M}$, et al. Recessive mutations in DGKE cause atypical hemolytic-uremic syndrome. Nat Genet (2013) 45:531-6. doi:10.1038/ng.2590

5. Zuber J, Le Quintrec M, Morris H, Frémeaux-Bacchi V, Loirat C, Legendre C. Targeted strategies in the prevention and management of atypical HUS recurrence after kidney transplantation. Transplant Rev (Orlando) (2013) 27:117-25. doi:10.1016/j.trre.2013.07.003

6. Cameron JS, Vick R. Letter: plasma-C3 in haemolytic-uraemic syndrome and thrombotic thrombocytopenic purpura. Lancet (1973) 2:975. doi:10.1016/ S0140-6736(73)92645-7

7. Zuber J, Le Quintrec M, Sberro-Soussan R, Loirat C, Frémeaux-Bacchi V, Legendre C. New insights into postrenal transplant hemolytic uremic syndrome. Nat Rev Nephrol (2011) 7:23-35. doi:10.1038/nrneph.2010.155

8. Skerka C, Chen Q, Fremeaux-Bacchi V, Roumenina LT. Complement factor H related proteins (CFHRs). Mol Immunol (2013) 56:170-80. doi:10.1016/j. molimm.2013.06.001

9. Joseph C, Gattineni J. Complement disorders and hemolytic uremic syndrome. Curr Opin Pediatr (2013) 25:209-15. doi:10.1097/MOP.0b013e32835df48a

10. Goicoechea de Jorge E, Harris CL, Esparza-Gordillo J, Carreras L, Arranz EA, Garrido CA, et al. Gain-of-function mutations in complement factor B are associated with atypical hemolytic uremic syndrome. Proc Natl Acad Sci U S A (2007) 104:240-5. doi:10.1073/pnas.0603420103

11. Frémeaux-Bacchi V, Miller EC, Liszewski MK, Strain L, Blouin J, Brown AL, et al. Mutations in complement C3 predispose to development of atypical hemolytic uremic syndrome. Blood (2008) 112:4948-52. doi:10.1182/blood2008-01-133702

12. Delvaeye M, Noris M, De Vriese A, Esmon CT, Esmon NL, Ferrell G, et al. Thrombomodulin mutations in atypical hemolytic-uremic syndrome. $N$ Engl J Med (2009) 361:345-57. doi:10.1056/NEJMoa0810739

13. Esparza-Gordillo J, Goicoechea de Jorge E, Buil A, Carreras Berges L, LópezTrascasa M, Sánchez-Corral P, et al. Predisposition to atypical hemolytic uremic syndrome involves the concurrence of different susceptibility alleles in the regulators of complement activation gene cluster in 1q32. Hum Mol Genet (2005) 14:703-12. doi:10.1093/hmg/ddi099

14. Esparza-Gordillo J, Jorge EG, Garrido CA, Carreras L, López-Trascasa M, Sánchez-Corral P, et al. Insights into hemolytic uremic syndrome: segregation of three independent predisposition factors in a large, multiple affected pedigree. Mol Immunol (2006) 43:1769-75. doi:10.1016/j.molimm.2005.11.008

15. Fremeaux-Bacchi V, Kemp EJ, Goodship JA, Dragon-Durey MA, Strain L, Loirat $\mathrm{C}$, et al. The development of atypical haemolytic-uraemic syndrome is influenced by susceptibility factors in factor $\mathrm{H}$ and membrane cofactor protein: evidence from two independent cohorts. J Med Genet (2005) 42:852-6. doi:10.1136/jmg.2005.030783

16. Rodriguez E, Rallapalli PM, Osborne AJ, Perkins SJ. New functional and structural insights from updated mutational databases for complement factor $\mathrm{H}$, factor I, membrane cofactor protein and C3. Biosci Rep (2014) 34(5):e00146. doi:10.1042/BSR20140117

17. Caprioli J, Noris M, Brioschi S, Pianetti G, Castelletti F, Bettinaglio P, et al. Genetics of HUS: the impact of MCP, CFH, and IF mutations on clinical presentation, response to treatment, and outcome. Blood (2006) 108:1267-79. doi:10.1182/blood-2005-10-007252

18. Caprioli J, Bettinaglio P, Zipfel PF, Amadei B, Daina E, Gamba S, et al. The molecular basis of familial hemolytic uremic syndrome: mutation analysis of factor $\mathrm{H}$ gene reveals a hot spot in short consensus repeat 20. J Am Soc Nephrol (2001) 12:297-307.

19. Noris M, Caprioli J, Bresin E, Mossali C, Pianetti G, Gamba S, et al. Relative role of genetic complement abnormalities in sporadic and familial aHUS and their impact on clinical phenotype. Clin J Am Soc Nephrol (2010) 5:1844-59. doi:10.2215/CJN.02210310

20. Kavanagh D, Kemp EJ, Mayland E, Winney RJ, Duffield JS, Warwick G, et al. Mutations in complement factor I predispose to development of atypical hemolytic uremic syndrome. J Am Soc Nephrol (2005) 16:2150-5. doi:10.1681/ ASN.2005010103

21. Kavanagh D, Richards A, Noris M, Hauhart R, Liszewski MK, Karpman $\mathrm{D}$, et al. Characterization of mutations in complement factor I (CFI) associated with hemolytic uremic syndrome. Mol Immunol (2008) 45:95-105. doi:10.1016/j.molimm.2007.05.004

22. Moore I, Strain L, Pappworth I, Kavanagh D, Barlow PN, Herbert AP, et al. Association of factor $\mathrm{H}$ autoantibodies with deletions of CFHR1, CFHR3, CFHR4, and with mutations in CFH, CFI, CD46, and C3 in patients with atypical hemolytic uremic syndrome. Blood (2010) 115:379-87. doi:10.1182/ blood-2009-05-221549

23. Hofer J, Janecke AR, Zimmerhackl LB, Riedl M, Rosales A, Giner T, et al. Complement factor $\mathrm{H}$-related protein 1 deficiency and factor $\mathrm{H}$ antibodies 
in pediatric patients with atypical hemolytic uremic syndrome. Clin J Am Soc Nephrol (2013) 8:407-15. doi:10.2215/CJN.01260212

24. Sellier-Leclerc AL, Fremeaux-Bacchi V, Dragon-Durey MA, Macher MA, Niaudet P, Guest G, et al. Differential impact of complement mutations on clinical characteristics in atypical hemolytic uremic syndrome. J Am Soc Nephrol (2007) 18:2392-400. doi:10.1681/ASN.2006080811

25. Richards A, Kemp EJ, Liszewski MK, Goodship JA, Lampe AK, Decorte R, et al. Mutations in human complement regulator, membrane cofactor protein (CD46), predispose to development of familial hemolytic uremic syndrome. Proc Natl Acad Sci U S A (2003) 100:12966-71. doi:10.1073/pnas.2135497100

26. Bienaime F, Dragon-Durey MA, Regnier CH, Nilsson SC, Kwan WH, Blouin $\mathrm{J}$, et al. Mutations in components of complement influence the outcome of Factor I-associated atypical hemolytic uremic syndrome. Kidney Int (2010) 77:339-49. doi:10.1038/ki.2009.472

27. Noris M, Bresin E, Mele C, Remuzzi G. Atypical hemolytic-uremic syndrome. In: Pagon RA, Adam MP, Ardinger HH, Bird TD, Dolan CR, Fong C-T, et al. editors. GeneReviews ${ }^{\circledR}$ [Internet]. Seattle, WA: University of Washington; 19932014 (2013). p. 9-26.

28. Nilsson SC, Kalchishkova N, Trouw LA, Fremeaux-Bacchi V, Villoutreix BO, Blom AM. Mutations in complement factor I as found in atypical hemolytic uremic syndrome lead to either altered secretion or altered function of factor I. Eur J Immunol (2010) 40:172-85. doi:10.1002/eji.200939280

29. Sinibaldi S, Guzzo I, Piras R, Bresin E, Emma F, Dello Strologo L. Posttransplant recurrence of atypical hemolytic uremic syndrome in a patient with thrombomodulin mutation. Pediatr Transplant (2013) 17:E177-81. doi: $10.1111 /$ petr.12151

30. Tawadrous H, Maga T, Sharma J, Kupferman J, Smith RJ, Schoeneman M. A novel mutation in the complement factor B gene (CFB) and atypical hemolytic uremic syndrome. Pediatr Nephrol (2010) 25:947-51. doi:10.1007/s00467-0091415-3

31. Loirat C, Fremeaux-Bacchi V. Atypical hemolytic uremic syndrome. Orphanet J Rare Dis (2011) 6:60. doi:10.1186/1750-1172-6-60

32. Loirat C, Noris M, Fremeaux-Bacchi V. Complement and the atypical hemolytic uremic syndrome in children. Pediatr Nephrol (2008) 23:1957-72. doi:10.1007/ s00467-008-0872-4

33. Maga TK, Nishimura CJ, Weaver AE, Frees KL, Smith RJ. Mutations in alternative pathway complement proteins in American patients with atypical hemolytic uremic syndrome. Hum Mutat (2010) 31:E1445-60. doi:10.1002/ humu. 21256

34. Martinez-Barricarte R, Pianetti G, Gautard R, Misselwitz J, Strain L, FremeauxBacchi V, et al. The complement factor H R1210C mutation is associated with atypical hemolytic uremic syndrome. J Am Soc Nephrol (2008) 19:639-46. doi:10.1681/ASN.2007080923

35. Abarrategui-Garrido C, Martínez-Barricarte R, López-Trascasa M, de Córdoba SR, Sánchez-Corral P. Characterization of complement factor H-related (CFHR) proteins in plasma reveals novel genetic variations of CFHR1 associated with atypical hemolytic uremic syndrome. Blood (2009) 114:4261-71. doi:10.1182/blood-2009-05-223834

36. Skerka C, Zipfel PF. Complement factor $\mathrm{H}$ related proteins in immune diseases. Vaccine (2008) 26(Suppl 8):I9-14. doi:10.1016/j.vaccine.2008.11.021

37. Venables JP, Strain L, Routledge D, Bourn D, Powell HM, Warwicker P, et al. Atypical haemolytic uraemic syndrome associated with a hybrid complement gene. PLoS Med (2006) 3:e431. doi:10.1371/journal.pmed.0030431

38. Francis NJ, McNicholas B, Awan A, Waldron M, Reddan D, Sadlier D, et al. A novel hybrid CFH/CFHR3 gene generated by a microhomologymediated deletion in familial atypical hemolytic uremic syndrome. Blood (2012) 119:591-601. doi:10.1182/blood-2011-03-339903

39. Józsi M, Licht C, Strobel S, Zipfel SL, Richter H, Heinen S, et al. Factor H autoantibodies in atypical hemolytic uremic syndrome correlate with CFHR1/CFHR3 deficiency. Blood (2008) 111:1512-4. doi:10.1182/blood-2007-09-109876

40. Dragon-Durey MA, Blanc C, Marliot F, Loirat C, Blouin J, Sautes-Fridman C, et al. The high frequency of complement factor $\mathrm{H}$ related CFHR1 gene deletion is restricted to specific subgroups of patients with atypical haemolytic uraemic syndrome. J Med Genet (2009) 46:447-50. doi:10.1136/jmg.2008.064766

41. Zipfel PF, Mache C, Müller D, Licht C, Wigger M, Skerka C, et al. DEAPHUS: deficiency of CFHR plasma proteins and autoantibody-positive form of hemolytic uremic syndrome. Pediatr Nephrol (2010) 25:2009-19. doi:10.1007/ s00467-010-1446-9
42. Westra D, Wetzels JF, Volokhina EB, van den Heuvel LP, van de Kar NC. A new era in the diagnosis and treatment of atypical haemolytic uraemic syndrome. Neth J Med (2012) 70:121-9.

43. Loirat $\mathrm{C}$, Niaudet $\mathrm{P}$. The risk of recurrence of hemolytic uremic syndrome after renal transplantation in children. Pediatr Nephrol (2003) 18:1095-101. doi:10.1007/s00467-003-1289-8

44. Hébert D, Kim EM, Sibley RK, Mauer MS. Post-transplantation outcome of patients with hemolytic-uremic syndrome: update. Pediatr Nephrol (1991) 5:162-7. doi:10.1007/BF00852876

45. Hebert D, Sibley RK, Mauer SM. Recurrence of hemolytic uremic syndrome in renal transplant recipients. Kidney Int Suppl (1986) 19:S51-8.

46. Artz MA, Steenbergen EJ, Hoitsma AJ, Monnens LA, Wetzels JF. Renal transplantation in patients with hemolytic uremic syndrome: high rate of recurrence and increased incidence of acute rejections. Transplantation (2003) 76:821-6. doi:10.1097/01.TP.0000085083.74065.1B

47. Lahlou A, Lang P, Charpentier B, Barrou B, Glotz D, Baron C, et al. Hemolytic uremic syndrome. Recurrence after renal transplantation. Groupe Cooperatif de l'Ile-de-France (GCIF). Medicine (Baltimore) (2000) 79:90-102. doi:10.1097/00005792-200003000-00003

48. Quan A, Sullivan EK, Alexander SR. Recurrence of hemolytic uremic syndrome after renal transplantation in children: a report of the North American Pediatric Renal Transplant Cooperative Study. Transplantation (2001) 72:742-5. doi:10.1097/00007890-200108270-00033

49. Bresin E, Daina E, Noris M, Castelletti F, Stefanov R, Hill P, et al. Outcome of renal transplantation in patients with non-Shiga toxin-associated hemolytic uremic syndrome: prognostic significance of genetic background. Clin J Am Soc Nephrol (2006) 1:88-99. doi:10.2215/CJN.00050505

50. Loirat C, Fremeaux-Bacchi V. Hemolytic uremic syndrome recurrence after renal transplantation. Pediatr Transplant (2008) 12:619-29. doi:10.1111/j. 1399-3046.2008.00910.x

51. Le Quintrec M, Zuber J, Moulin B, Kamar N, Jablonski M, Lionet A, et al. Complement genes strongly predict recurrence and graft outcome in adult renal transplant recipients with atypical hemolytic and uremic syndrome. Am J Transplant (2013) 13:663-75. doi:10.1111/ajt.12077

52. Kwon T, Dragon-Durey MA, Macher MA, Baudouin V, Maisin A, Peuchmaur $\mathrm{M}$, et al. Successful pre-transplant management of a patient with anti-factor $\mathrm{H}$ autoantibodies-associated haemolytic uraemic syndrome. Nephrol Dial Transplant (2008) 23:2088-90. doi:10.1093/ndt/gfn063

53. Le Quintrec M, Zuber J, Noel LH, Thervet E, Frémeaux-Bacchi V, Niaudet $P$, et al. Anti-Factor $\mathrm{H}$ autoantibodies in a fifth renal transplant recipient with atypical hemolytic and uremic syndrome. Am J Transplant (2009) 9:1223-9. doi:10.1111/j.1600-6143.2009.02586.x

54. Waters AM, Pappworth I, Marchbank K, Bockenhauer D, Tullus K, Pickering $\mathrm{MC}$, et al. Successful renal transplantation in factor $\mathrm{H}$ autoantibody associated HUS with CFHR1 and 3 deficiency and CFH variant G2850T. Am J Transplant (2010) 10:168-72. doi:10.1111/j.1600-6143.2009.02870.x

55. Fremeaux-Bacchi V, Dragon-Durey MA, Blouin J, Vigneau C, Kuypers D, Boudailliez B, et al. Complement factor I: a susceptibility gene for atypical haemolytic uraemic syndrome. J Med Genet (2004) 41:e84. doi:10.1136/jmg. 2004.019083

56. Chan MR, Thomas CP, Torrealba JR, Djamali A, Fernandez LA, Nishimura CJ, et al. Recurrent atypical hemolytic uremic syndrome associated with factor I mutation in a living related renal transplant recipient. Am J Kidney Dis (2009) 53:321-6. doi:10.1053/j.ajkd.2008.06.027

57. Geelen J, van den Dries K, Roos A, van de Kar N, de Kat Angelino C, Klasen I, et al. A missense mutation in factor I (IF) predisposes to atypical haemolytic uraemic syndrome. Pediatr Nephrol (2007) 22:371-5. doi:10.1007/s00467-0060320-2

58. Nilsson SC, Karpman D, Vaziri-Sani F, Kristoffersson AC, Salomon R, Provot F, et al. A mutation in factor I that is associated with atypical hemolytic uremic syndrome does not affect the function of factor I in complement regulation. Mol Immunol (2007) 44:1835-44. doi:10.1016/j.molimm. 2006.10.005

59. Davin JC, Buter N, Groothoff J, van Wijk J, Bouts A, Strain L, et al. Prophylactic plasma exchange in CD46-associated atypical haemolytic uremic syndrome. Pediatr Nephrol (2009) 24:1757-60. doi:10.1007/s00467-009-1188-8

60. Fremeaux-Bacchi V, Moulton EA, Kavanagh D, Dragon-Durey MA, Blouin J, Caudy A, et al. Genetic and functional analyses of membrane cofactor protein 
(CD46) mutations in atypical hemolytic uremic syndrome. J Am Soc Nephrol (2006) 17:2017-25. doi:10.1681/ASN.2005101051

61. Bresin E, Rurali E, Caprioli J, Sanchez-Corral P, Fremeaux-Bacchi V, Rodriguez de Cordoba S, et al. Combined complement gene mutations in atypical hemolytic uremic syndrome influence clinical phenotype. J Am Soc Nephrol (2013) 24:475-86. doi:10.1681/ASN.2012090884

62. Matar D, Naqvi F, Racusen LC, Carter-Monroe N, Montgomery RA, Alachkar N. Atypical hemolytic uremic syndrome recurrence after kidney transplantation. Transplantation (2014) 98(11):1205-12. doi:10.1097/TP.0000000000000200

63. Pratt JR, Basheer SA, Sacks SH. Local synthesis of complement component C3 regulates acute renal transplant rejection. Nat Med (2002) 8:582-7. doi:10.1038/nm0602-582

64. Zheng X, Feng B, Chen G, Zhang X, Li M, Sun H, et al. Preventing renal ischemia-reperfusion injury using small interfering RNA by targeting complement 3 gene. Am J Transplant (2006) 6:2099-108. doi:10.1111/j.1600-6143. 2006.01427.x

65. Roumenina LT, Jablonski M, Hue C, Blouin J, Dimitrov JD, Dragon-Durey MA, et al. Hyperfunctional C3 convertase leads to complement deposition on endothelial cells and contributes to atypical hemolytic uremic syndrome. Blood (2009) 114:2837-45. doi:10.1182/blood-2009-01-197640

66. Fremeaux-Bacchi V, Fakhouri F, Garnier A, Bienaimé F, Dragon-Durey MA, Ngo S, et al. Genetics and outcome of atypical hemolytic uremic syndrome: a nationwide French series comparing children and adults. Clin J Am Soc Nephrol (2013) 8:554-62. doi:10.2215/CJN.04760512

67. Ducloux D, Rebibou JM, Semhoun-Ducloux S, Jamali M, Fournier V, BressonVautrin C, et al. Recurrence of hemolytic-uremic syndrome in renal transplant recipients: a meta-analysis. Transplantation (1998) 65:1405-7. doi:10. 1097/00007890-199805270-00023

68. Naesens M, Li L, Ying L, Sansanwal P, Sigdel TK, Hsieh SC, et al. Expression of complement components differs between kidney allografts from living and deceased donors. J Am Soc Nephrol (2009) 20:1839-51. doi:10.1681/ASN. 2008111145

69. van Werkhoven MB, Damman J, van Dijk MC, Daha MR, de Jong IJ, Leliveld A, et al. Complement mediated renal inflammation induced by donor brain death: role of renal C5a-C5aR interaction. Am J Transplant (2013) 13:875-82. doi:10.1111/ajt.12130

70. Snoeijs MG, Vink H, Voesten N, Christiaans MH, Daemen JW, Peppelenbosch AG, et al. Acute ischemic injury to the renal microvasculature in human kidney transplantation. Am J Physiol Renal Physiol (2010) 299:F1134-40. doi:10.1152/ajprenal.00158.2010

71. Olie KH, Goodship TH, Verlaak R, Florquin S, Groothoff JW, Strain L, et al. Posttransplantation cytomegalovirus-induced recurrence of atypical hemolytic uremic syndrome associated with a factor $\mathrm{H}$ mutation: successful treatment with intensive plasma exchanges and ganciclovir. Am J Kidney Dis (2005) 45:e12-5. doi:10.1053/j.ajkd.2004.09.012

72. Al-Akash SI, Almond PS, Savell VH Jr, Gharaybeh SI, Hogue C. Eculizumab induces long-term remission in recurrent post-transplant HUS associated with C3 gene mutation. Pediatr Nephrol (2011) 26:613-9. doi:10.1007/s00467010-1708-6

73. Printza N, Roilides E, Kotsiou M, Zafeiriou D, Hatzidimitriou V, Papachristou F. Pandemic influenza A (H1N1) 2009-associated hemolytic uremic syndrome. Pediatr Nephrol (2011) 26:143-4. doi:10.1007/s00467-010-1603-1

74. Trachtman H, Sethna C, Epstein R, D’Souza M, Rubin LG, Ginocchio CC. Atypical hemolytic uremic syndrome associated with $\mathrm{H} 1 \mathrm{~N} 1$ influenza A virus infection. Pediatr Nephrol (2011) 26:145-6. doi:10.1007/s00467-0101636-5

75. Murer L, Zacchello G, Bianchi D, Dall'Amico R, Montini G, Andreetta B, et al. Thrombotic microangiopathy associated with parvovirus B 19 infection after renal transplantation. J Am Soc Nephrol (2000) 11:1132-7.

76. Petrogiannis-Haliotis T, Sakoulas G, Kirby J, Koralnik IJ, Dvorak AM, Monahan-Earley R, et al. BK-related polyomavirus vasculopathy in a renal-transplant recipient. N Engl J Med (2001) 345:1250-5. doi:10.1056/ NEJMoa010319

77. Weitz M, Amon O, Bassler D, Koenigsrainer A, Nadalin S. Prophylactic eculizumab prior to kidney transplantation for atypical hemolytic uremic syndrome. Pediatr Nephrol (2011) 26:1325-9. doi:10.1007/s00467-011-1879-9

78. Nester C, Stewart Z, Myers D, Jetton J, Nair R, Reed A, et al. Pre-emptive eculizumab and plasmapheresis for renal transplant in atypical hemolytic uremic syndrome. Clin J Am Soc Nephrol (2011) 6:1488-94. doi:10.2215/CJN. 10181110

79. Al-Massarani G, Vacher-Coponat H, Paul P, Widemann A, Arnaud L, Loundou A, et al. Impact of immunosuppressive treatment on endothelial biomarkers after kidney transplantation. Am J Transplant (2008) 8:2360-7. doi:10.1111/j. 1600-6143.2008.02399.x

80. Miriuka SG, Rao V, Peterson M, Tumiati L, Delgado DH, Mohan R, et al. mTOR inhibition induces endothelial progenitor cell death. Am J Transplant (2006) 6:2069-79. doi:10.1111/j.1600-6143.2006.01433.x

81. Ponticelli C. De novo thrombotic microangiopathy. An underrated complication of renal transplantation. Clin Nephrol (2007) 67:335-40. doi:10.5414/ CNP67335

82. Le Quintrec M, Lionet A, Kamar N, Karras A, Barbier S, Buchler M, et al. Complement mutation-associated de novo thrombotic microangiopathy following kidney transplantation. Am J Transplant (2008) 8:1694-701. doi:10. 1111/j.1600-6143.2008.02297.x

83. Schwimmer J, Nadasdy TA, Spitalnik PF, Kaplan KL, Zand MS. De novo thrombotic microangiopathy in renal transplant recipients: a comparison of hemolytic uremic syndrome with localized renal thrombotic microangiopathy. Am J Kidney Dis (2003) 41:471-9. doi:10.1053/ajkd.2003.50058

84. Wilson CH, Brown AL, White SA, Goodship TH, Sheerin NS, Manas DM. Successful treatment of de novo posttransplant thrombotic microangiopathy with eculizumab. Transplantation (2011) 92:e42-3. doi:10.1097/TP. 0b013e318230c0bd

85. Sadler JE, Moake JL, Miyata T, George JN. Recent advances in thrombotic thrombocytopenic purpura. Hematology Am Soc Hematol Educ Program (2004) 2004(1):407-23. doi:10.1182/asheducation-2004.1.407

86. Gandhi K, Aronow WS, Desai H, Amin H, Sharma M, Lai HM, et al. Cardiovascular manifestations in patients with thrombotic thrombocytopenic purpura: a single-center experience. Clin Cardiol (2010) 33:213-6. doi:10.1002/clc.20731

87. Olie KH, Florquin S, Groothoff JW, Verlaak R, Strain L, Goodship TH, et al. Atypical relapse of hemolytic uremic syndrome after transplantation. Pediatr Nephrol (2004) 19:1173-6. doi:10.1007/s00467-004-1565-2

88. Stevenson S, Mallett A, Oliver K, Hyland V, Hawley C, Malmanche T, et al. Atypical HUS associated with severe, unexpected antibody-mediated rejection post kidney transplant. Nephrology (Carlton) (2014) 19(Suppl 1):22-6. doi:10.1111/nep.12195

89. Noone D, Al-Matrafi J, Tinckam K, Zipfel PF, Herzenberg AM, Thorner PS, et al. Antibody mediated rejection associated with complement factor h-related protein 3/1 deficiency successfully treated with eculizumab. Am J Transplant (2012) 12:2546-53. doi:10.1111/j.1600-6143.2012.04124.x

90. Zuber J, Fakhouri F, Roumenina LT, Loirat C, Frémeaux-Bacchi V, French Study Group for aHUS/C3G. Use of eculizumab for atypical haemolytic uraemic syndrome and C3 glomerulopathies. Nat Rev Nephrol (2012) 8:643-57. doi:10.1038/nrneph.2012.214

91. Davin JC, Strain L, Goodship TH. Plasma therapy in atypical haemolytic uremic syndrome: lessons from a family with a factor H mutation. Pediatr Nephrol (2008) 23:1517-21. doi:10.1007/s00467-008-0833-y

92. Loirat C, Saland J, Bitzan M. Management of hemolytic uremic syndrome. Presse Med (2012) 41(3 Pt 2):e115-35. doi:10.1016/j.lpm.2011.11.013

93. Remuzzi G, Ruggenenti P, Codazzi D, Noris M, Caprioli J, Locatelli G, et al. Combined kidney and liver transplantation for familial haemolytic uraemic syndrome. Lancet (2002) 359:1671-2. doi:10.1016/S0140-6736(02)08560-4

94. Remuzzi G, Ruggenenti P, Colledan M, Gridelli B, Bertani A, Bettinaglio P, et al. Hemolytic uremic syndrome: a fatal outcome after kidney and liver transplantation performed to correct factor h gene mutation. Am J Transplant (2005) 5:1146-50. doi:10.1111/j.1600-6143.2005.00783.x

95. Lennon FE, Singleton PA. Hyaluronan regulation of vascular integrity. Am J Cardiovasc Dis (2011) 1:200-13.

96. Rehm M, Bruegger D, Christ F, Conzen P, Thiel M, Jacob M, et al. Shedding of the endothelial glycocalyx in patients undergoing major vascular surgery with global and regional ischemia. Circulation (2007) 116:1896-906. doi:10.1161/CIRCULATIONAHA.106.684852

97. Saland J. Liver-kidney transplantation to cure atypical HUS: still an option post-eculizumab? Pediatr Nephrol (2014) 29:329-32. doi:10.1007/s00467-0132722-2

98. Zuber J, Le Quintrec M, Krid S, Bertoye C, Gueutin V, Lahoche A, et al. Eculizumab for atypical hemolytic uremic syndrome recurrence in renal 
transplantation. Am J Transplant (2012) 12:3337-54. doi:10.1111/j.1600-6143. 2012.04252.x

99. Chatelet V, Frémeaux-Bacchi V, Lobbedez T, Ficheux M, Hurault de Ligny B. Safety and long-term efficacy of eculizumab in a renal transplant patient with recurrent atypical hemolytic-uremic syndrome. Am J Transplant (2009) 9:2644-5. doi:10.1111/j.1600-6143.2009.02817.x

100. Koskinen AR, Tukiainen E, Arola J, Nordin A, Höckerstedt HK, Nilsson B, et al. Complement activation during liver transplantation-special emphasis on patients with atypical hemolytic uremic syndrome. Am J Transplant (2011) 11:1885-95. doi:10.1111/j.1600-6143.2011.03612.x

101. de Vries DK, van der Pol P, van Anken GE, van Gijlswijk DJ, Damman J, Lindeman $\mathrm{JH}$, et al. Acute but transient release of terminal complement complex after reperfusion in clinical kidney transplantation. Transplantation (2013) 95:816-20. doi:10.1097/TP.0b013e31827e31c9

102. Kelly RJ, Hill A, Arnold LM, Brooksbank GL, Richards SJ, Cullen M, et al. Long-term treatment with eculizumab in paroxysmal nocturnal hemoglobinuria: sustained efficacy and improved survival. Blood (2011) 117:6786-92. doi:10.1182/blood-2011-02-333997

103. de Jorge EG, Macor P, Paixão-Cavalcante D, Rose KL, Tedesco F, Cook HT, et al. The development of atypical hemolytic uremic syndrome depends on complement C5. J Am Soc Nephrol (2011) 22:137-45. doi:10.1681/ASN.2010050451

104. Nurnberger J, Philipp T, Witzke O, Opazo Saez A, Vester U, Baba HA, et al. Eculizumab for atypical hemolytic-uremic syndrome. N Engl J Med (2009) 360:542-4. doi:10.1056/NEJMc0808527

105. Larrea CF, Cofan F, Oppenheimer F, Campistol JM, Escolar G, Lozano M. Efficacy of eculizumab in the treatment of recurrent atypical hemolyticuremic syndrome after renal transplantation. Transplantation (2010) 89:903-4. doi:10.1097/TP.0b013e3181ccd80d

106. Alachkar N, Bagnasco SM, Montgomery RA. Eculizumab for the treatment of two recurrences of atypical hemolytic uremic syndrome in a kidney allograft. Transpl Int (2012) 25:e93-5. doi:10.1111/j.1432-2277.2012.01497.x

107. Legendre C, Sberro-Soussan R, Zuber J, Rabant M, Loupy A, Timsit MO, et al. Eculizumab in renal transplantation. Transplant Rev (Orlando) (2013) 27:90-2. doi:10.1016/j.trre.2013.04.002

108. Davin JC, Gracchi V, Bouts A, Groothoff J, Strain L, Goodship T. Maintenance of kidney function following treatment with eculizumab and discontinuation of plasma exchange after a third kidney transplant for atypical hemolytic uremic syndrome associated with a CFH mutation. Am J Kidney Dis (2010) 55:708-11. doi:10.1053/j.ajkd.2009.08.011

109. Miller RB, Burke BA, Schmidt WJ, Gillingham KJ, Matas AJ, Mauer M, et al. Recurrence of haemolytic-uraemic syndrome in renal transplants: a singlecentre report. Nephrol Dial Transplant (1997) 12:1425-30. doi:10.1093/ndt/ 12.7.1425

110. Xie L, Nester CM, Reed AI, Zhang Y, Smith RJ, Thomas CP. Tailored eculizumab therapy in the management of complement factor H-mediated atypical hemolytic uremic syndrome in an adult kidney transplant recipient: a case report. Transplant Proc (2012) 44:3037-40. doi:10.1016/j.transproceed.2012. 07.141

111. Sakai M, Ikezoe T, Bandobashi K, Togitani K, Yokoyama A. Successful treatment of transplantation-associated thrombotic microangiopathy with recombinant human soluble thrombomodulin. Bone Marrow Transplant (2010) 45:803-5. doi:10.1038/bmt.2009.242

112. Wagner E, Frank MM. Therapeutic potential of complement modulation. Nat Rev Drug Discov (2010) 9:43-56. doi:10.1038/nrd3011

Conflict of Interest Statement: Nada Alachkar received one-time consultation reimbursement from Alexion Company in July 2012. Sami Alasfar declares no commercial or financial relationships that could be construed as a potential conflict of interest.

Received: 18 October 2014; accepted: 29 November 2014; published online: 12 December 2014.

Citation: Alasfar S and Alachkar N (2014) Atypical hemolytic uremic syndrome postkidney transplantation: two case reports and review of the literature. Front. Med. 1:52. doi: 10.3389/fmed.2014.00052

This article was submitted to Nephrology, a section of the journal Frontiers in Medicine. Copyright (c) 2014 Alasfar and Alachkar. This is an open-access article distributed under the terms of the Creative Commons Attribution License (CC BY). The use, distribution or reproduction in other forums is permitted, provided the original author $(s)$ or licensor are credited and that the original publication in this journal is cited, in accordance with accepted academic practice. No use, distribution or reproduction is permitted which does not comply with these terms. 